Centre interuniversitaire de recherche en économie quantitative

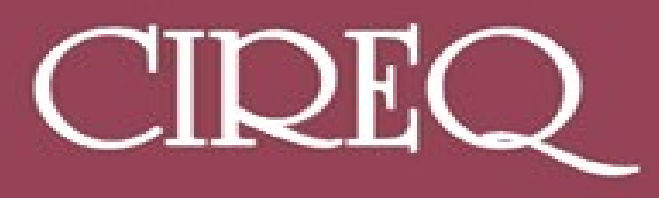

Cahier 07-2010

SHOULD THE GOOD AND THE SELFISH BE TAXED DIFFERENTLY?

Ngo van LONG and Frank STÄHLER 


\section{CIREQ}

Le Centre interuniversitaire de recherche en économie quantitative (CIREQ) regroupe des chercheurs dans les domaines de l'économétrie, la théorie de la décision, la macroéconomie et les marchés financiers, la microéconomie appliquée et l'économie expérimentale ainsi que l'économie de l'environnement et des ressources naturelles. Ils proviennent principalement des universités de Montréal, McGill et Concordia. Le CIREQ offre un milieu dynamique de recherche en économie quantitative grâce au grand nombre d'activités qu'il organise (séminaires, ateliers, colloques) et de collaborateurs qu'il reçoit chaque année.

The Center for Interuniversity Research in Quantitative Economics (CIREQ) regroups researchers in the fields of econometrics, decision theory, macroeconomics and financial markets, applied microeconomics and experimental economics, and environmental and natural resources economics. They come mainly from the Université de Montréal, McGill University and Concordia University. CIREQ offers a dynamic environment of research in quantitative economics thanks to the large number of activities that it organizes (seminars, workshops, conferences) and to the visitors it receives every year.

\section{Cahier 07-2010}

\section{SHOULD THE GOOD AND THE SELFISH BE TAXED DIFFERENTLY?}

Ngo van LONG and Frank STÄHLER

CIREQ, Université de Montréal C.P. 6128, succursale Centre-ville Montréal (Québec) H3C $3 J 7$ Canada
Universite th de Montréal 
Dépôt légal - Bibliothèque nationale du Canada, 2010, ISSN 0821-4441

Dépôt légal - Bibliothèque et Archives nationales du Québec, 2010

ISBN-13 : 978-2-89382-595-3 


\title{
Should the Good and the Selfish be Taxed Differently?
}

\author{
Ngo Van Long ${ }^{1}$
}

Frank Stähler ${ }^{2}$

24th February 2010

${ }^{1}$ CIREQ and Department of Economics, McGill University, Montreal H3A 2T7, Canada, email: ngo.long@mcgill.ca

${ }^{2}$ Department of Economics, University of Würzburg. (frank.staehler@uniwuerzburg.de.) 


\begin{abstract}
This paper considers an environment where individual actions have externalities, and where there are two types of agents: socially responsible agents (the good) and selfish agents. Selfish agents have payoff functions that do not take into account social welfare. The payoff of a socially responsible agent is a linear combination of (i) social welfare, and (ii) the payoff of a selfish agent. We demonstrate that the corrective tax rates that maximize social welfare do not depend on the degree of social responsibility of socially responsible agents. Hence, the good and the selfish should not be taxed differently.
\end{abstract}

JEL-Classification: H21.

Keywords: Efficiency-inducing taxation, externalities, social responsibility. 
Two souls alas! are dwelling in my breast;

And each is fain to leave its brother.

The one, fast clinging, to the world adheres

With clutching organs, in love's sturdy lust;

The other strongly lifts itself from dust

To yonder high, ancestral spheres.

Oh, are there spirits hovering near,

That ruling weave, twixt earth and heaven are rife,

Descend! come from the golden atmosphere

And lead me hence to new and varied life!

Johann Wolfgang von Goethe, Faust

\section{Introduction}

How should taxation treat individuals that have two souls, one selfish and the other one socially responsible? To our knowledge, this question has not been formally discussed in the optimal taxation literature. This lack of interest is somewhat surprising, given the frequent appeal that good citizens should have a sense of social responsibility. Of course, an appeal for social responsibility is all that can be done if individual actions cannot be influenced by measures such as taxes and subsidies. But how should the government respond to the existence of (partially) socially responsible agents if it can influence individual actions? For example, should the government - if possible - make environmental taxes dependent on the degree of social responsibility? Is there another dimension to be taken into account when designing an optimal tax/subsidy scheme? Our paper demonstrates an invariance theorem: social responsibility does not play any role for policy design as long as all relevant actions can be taxed/subsidized and agents agree on "common sense", i.e., agree on what should be done for the group as a whole.

The issue of taxing activities which give rise to externalities has a longstanding tradition in economics. Since the early work of Pigou (1920), it is well-known that the outcome of individual actions is typically Pareto inefficient if individuals, in the pursuit of private interests, take actions that directly affect the wellbeing of others. This is true both in the case where 
there are no strategic interactions, and in the case where the group of individuals is small enough so that each takes into account the strategies of others. In the absence of co-ordination, selfish utility maximization normally results in a Nash equilibrium that is sub-optimal.

In order to internalize externalities and to increase social welfare, Pigou (1920) proposed a corrective tax (subsidy) for a negative (positive) externality. ${ }^{1}$ In this paper, we ask whether the optimal tax/subsidy scheme should be changed if a sub-group of individuals is not entirely selfish but has developed a sense of social responsibility. These "good" agents have "common sense"; they know what would be best for the whole group and take this into account when making decisions. We model their behavior such that their actions no longer aim at maximizing private utility; they seek to maximize a linear combination of private utility and social welfare. Should these agents be taxed differently? In this paper, we show that the good and the selfish should not be taxed differently.

The taxation literature does not seem to have touched this issue from this perspective but has focused on issues of fairness and redistribution. Fairness has been considered in the context of optimal taxation (Alesina and Angeletos, 2005, Fleurbaey and Maniquet, 2006, 2007), and experimental evidence suggests that agents are inequality averse (Ackert, Martinez-Vasquez and Rider, 2007) $)^{2}$. This literature is more concerned with redistribution, whereas we focus on allocational effects of taxation. We assume that issues of fairness and redistribution could be solved by another set of instruments.

The public economics literature does not lack invariance results so our contribution is not completely novel in this respect. Bergstrom, Blume and Varian (1986) have shown that restribution does not change the private pro-

\footnotetext{
${ }^{1}$ Alternative solutions include negotiation (Coase, 1960), and setting up a market for externalities (Arrow, 1970). In the case where the regulator does not have perfect information, implementation of efficient allocations as sub-game perfect equilibria can be achieved by mechanism designs, see Moore and Repullo (1988), Varian (1994). For a review of the literature on implementation under complete information, see Moore (1992).

${ }^{2}$ As for fair allocations, the literature has dealt with the existence and the properties of allocations which are considered fair. For example, Nishimura (2004) discusses this issue for allocations which are considered envy-free.
} 
vision of a public good as long as the set of contributors does not change. ${ }^{3}$ Atkinson and Stiglitz (1976) have demonstated that differential commodity taxes are unnecessary if an optimal non-linear income tax has been set. Our invariance theorem is closest to Becker's (1974) rotten kid theorem. He considers a setup in which a benevolent principal transfers resources to (selfish) agents, and shows that redistribution does not change consumption, as long as all of them are still supported, because selfish agents behave such that they maximize the group's income (see also Bergstrom, 1989). In our model, however, there is no benevolent principal on whom other (selfish) agents are dependent. Agents in our model do not differ in terms of their social status in a hierarchy but are instead different in terms of their social responsibility.

The remainder of the paper is organized as follows. Section 2 develops the basic model and the invariance theorem. Section 3 shows that our results extend to non-individualized taxes. Section 4 shows that our model is not restricted to the functional specification introduced in Section 2. Section 5 concludes.

\section{The model}

There are $n$ different agents. We label those agents who maximize their own payoff as selfish agents. Those agents who also take social welfare into account are labeled socially responsible agents; they are the good in our model. An individual agent will be denoted by $i$. Let $a_{i}$ be agent $i$ 's action, and let $\mathbf{a}_{-i}$ be the vector of actions of his rivals. ${ }^{4}$ Let us define the selfish component of each payoff first. The gross payoff of an agent $i$, before tax and ignoring any social responsibility, is

$$
u^{(i)}=u^{(i)}\left(a_{i}, \mathbf{a}_{-i}\right) .
$$

The function $u$ is assumed to be twice differentiable and strictly concave in $a_{i}$. We assume that the net payoff is the sum of the gross payoff $u$ and the tax

\footnotetext{
${ }^{3}$ See Groves and Ledyard (1997) for the pioneering paper on a mechanism to solve the free rider problem.

${ }^{4}$ Our results would not change if $a_{i}$ is the vector of actions of agent $i$, and $\mathbf{a}_{-i}$ denotes the matrix of actions of all other agents.
} 
bill $t_{i} a_{i}$, so that the payoff arising from the actions $\left(a_{i}, \mathbf{a}_{-i}\right)$ - again ignoring any social responsibility - is equal to

$$
\widetilde{u}^{(i)}\left(a_{i}, \mathbf{a}_{-i}\right)=u^{(i)}\left(a_{i}, \mathbf{a}_{-i}\right)-t_{i} a_{i}
$$

where $t_{i}$ is the agent-specific tax rate, imposed by the government, and taken as given by each agent. We assume that the tax bill depends linearly on the level of actions of agent $i .^{5}$ As for social welfare, we assume that it can be represented by

$$
W=W\left(a_{1}, a_{2}, \ldots, a_{n}\right)
$$

This specification assumes that all agents agree on its functional form; $W$ therefore represents what is called common sense. ${ }^{6}$

However, agents differ with respect to the degree by which they care about social welfare, and therefore we distinguish two different types of agents. The selfish type does not take social welfare into account, whereas the socially responsible agent does so to a certain extent. We suppose that any agent $i$ seeks to maximize the objective function

$$
V^{(i)}\left(\theta_{i}, a_{i}, \mathbf{a}_{-i}\right)=\left(1-\theta_{i}\right) \widetilde{u}^{(i)}\left(a_{i}, \mathbf{a}_{-i}\right)+\theta_{i} W\left(a_{i}, \mathbf{a}_{-i}\right), \quad 0 \leq \theta_{i}<1,
$$

where $\theta_{i}$ is $i$ 's the degree of social responsibility. A selfish agent is characterized by $\theta_{i}=0$, and a socially responsible agent is characterized by $\theta_{i}>0$. Note that agents differ in two dimensions: first, their gross payoff $u^{(i)}$ may differ even if the same actions are carried out by all agents, including themselves; second, agents may have different degrees of social responsibility even if their gross payoff functions coincide.

We begin our analysis with the case where all $n$ agents are selfish: $\theta_{i}=0$ for all $i$. This case will serve as a benchmark for the taxation of socially responsible agents. If the government had direct control over all the $a_{i}$ 's, it

\footnotetext{
${ }^{5}$ We will deal with non-individualized taxes in the subsequent section.

${ }^{6}$ Note that $W$ could be based on individual payoffs such that $W=$ $W\left[\widetilde{u}^{(1)}\left(a_{1}, \mathbf{a}_{-1}\right), \widetilde{u}^{(2)}\left(a_{2}, \mathbf{a}_{-2}\right), \ldots, \widetilde{u}^{(n)}\left(a_{n}, \mathbf{a}_{-n}\right)\right]$, but this is not required. See also our example in Section 3.
} 
would choose the vector $\mathbf{a}=\left(a_{1}, a_{2}, \ldots, a_{n}\right)$ to maximize welfare. The firstorder conditions for social welfare maximization consist of $n$ equations

$$
\frac{\partial W\left(\mathbf{a}^{*}\right)}{\partial a_{i}}=0, \text { for } i=1,2, \ldots, n .
$$

We assume that the second-order conditions are satisfied, and the first-order conditions uniquely identify the socially optimal vector $\mathbf{a}^{*}=\left(a_{1}^{*}, a_{2}^{*}, \ldots, a_{n}^{*}\right)$. We now show that the social optimum can be achieved by imposing an optimally chosen tax vector $\mathbf{t}^{*}=\left(t_{1}^{*}, t_{2}^{*}, \ldots, t_{n}^{*}\right)$; in particular, we shall prove the invariance result that the optimal tax vector is independent of the degree of social responsibility of any agent.

It will be convenient to use the following notation:

$$
W_{i}\left(a_{i}^{*}, \mathbf{a}_{-i}^{*}\right) \equiv \frac{\partial W\left(a_{i}^{*}, \mathbf{a}_{-i}^{*}\right)}{\partial a_{i}} \equiv \frac{\partial W\left(\mathbf{a}^{*}\right)}{\partial a_{i}} .
$$

A selfish agent $i$ takes as given the tax rate $t_{i}$ and the actions of all other agents, denoted by $\mathbf{a}_{-i}$. Maximizing $V^{(i)}\left(0, a_{i}, \mathbf{a}_{-i}\right)=\widetilde{u}^{(i)}\left(a_{i}, \mathbf{a}_{-i}\right)$ with respect to $a_{i}$ yields the first-order condition

$$
\frac{\partial \widetilde{u}^{(i)}\left(a_{i}, \mathbf{a}_{-i}\right)}{\partial a_{i}} \equiv \widetilde{u}_{i}^{(i)}\left(a_{i}, \mathbf{a}_{-i}\right) \equiv u_{i}^{(i)}\left(a_{i}, \mathbf{a}_{-i}\right)-t_{i}=0 .
$$

We arrive at

Lemma 1 The tax vector $\mathbf{t}^{*}=\left(t_{1}^{*}, t_{2}^{*}, \ldots, t_{n}^{*}\right)$ defined by

$$
t_{i}^{*}=u_{i}^{(i)}\left(a_{i}^{*}, \mathbf{a}_{-i}^{*}\right)-W_{i}\left(a_{i}^{*}, \mathbf{a}_{-i}^{*}\right)
$$

implements the socially optimal action vector as a Nash equilibrium of the game played by $n$ selfish agents.

Proof: Suppose that the government sets $t_{i}$ according to (3). The first-order condition (2) of agent $i$, evaluated at $t_{i}^{*}$, is

$$
u_{i}^{(i)}\left(a_{i}, \mathbf{a}_{-i}\right)-\left[u_{i}^{(i)}\left(a_{i}^{*}, \mathbf{a}_{-i}^{*}\right)-W_{i}\left(a_{i}^{*}, \mathbf{a}_{-i}^{*}\right)\right]=0 .
$$

Clearly, if agent $i$ thinks that all other agents choose $\mathbf{a}_{-i}=\mathbf{a}_{-i}^{*}$, then the first-order condition (4) is satisfied by choosing $a_{i}=a_{i}^{*}$. 
We now show that the same tax vector is optimal, and achieves the same action vector, even if one, some or all agents are socially responsible. Suppose that $t_{i}$ is set at $t_{i}^{*}$ as given by equation (3), and that a socially responsible agent $i$ believes that all other agents will choose $\mathbf{a}_{-i}^{*}$. Then the objective function of the socially responsible agent $i$ is

$$
V^{(i)}=\left(1-\theta_{i}\right)\left[u^{(i)}\left(a_{i}, \mathbf{a}_{-i}^{*}\right)-t_{i}^{*} a_{i}\right]+\theta_{i} W\left(a_{i}, \mathbf{a}_{-i}^{*}\right)
$$

and the corresponding first-order condition is

$$
\left(1-\theta_{i}\right)\left[u_{i}^{(i)}\left(a_{i}, \mathbf{a}_{-i}^{*}\right)-t_{i}^{*}\right]+\theta_{i} W_{i}\left(a_{i}, \mathbf{a}_{-i}^{*}\right)=0
$$

Clearly, this first-order condition is satisfied by choosing $a_{i}=a_{i}^{*}$, which is the socially optimal action defined by equation (1), for the term inside the square bracket is zero, and so is $W_{i}\left(a_{i}^{*}, \mathbf{a}_{-i}^{*}\right)$. We have proven

Proposition 1 The social optimum can be achieved as a Nash equilibrium by applying a vector of individual taxes. The optimal tax vector is independent of the vector of parameters $\theta_{i}$ that represents the degree of social responsibility. At the optimal tax, the Nash equilibrium action of each agent is independent of $\theta_{i}$.

If we require that the government's net tax receipt be zero, we must modify the tax bill of each agent, from $t_{i} a_{i}$ to $t_{i}\left(a_{i}-a_{i}^{*}\right)$ where $a_{i}^{*}$ is the socially optimal action. Then all the results go through, but no agent pays any tax in equilibrium. Clearly, $t_{i} a_{i}^{*}$ is a lump sum payment to the agent.

What is the intuition for our invariance theorem? Social responsibility implies that an agent has two souls. The selfish soul needs the tax in order to behave well; the other soul does not need it, but it also does no harm. Proposition 1 shows that the tax rate does not depend on the strength of the two souls; it is sufficient to deal with the bad one, the other will follow anyway. In the following sections, we will generalize this result.

\section{Non-Individualized Tax Schemes}

The last section's model and Proposition 1 have both relied on the feasibility of individual tax rates. In particular, the government is supposed to know 
each individual's gross payoff function. Usually, taxes are not individualized but depend on an observable level of certain actions. We will now explore how our results generalize if tax rate must not be individual-specific, but the government may use a tax scheme which depends on observable actions only. ${ }^{7}$

Let $T(a)$ denote the (non-individualized) tax scheme that depends on the observable level of actions which is denoted by $a .^{8}$ Since the tax is not individualized, the net payoff of agent $i$ is now equal to

$$
\widetilde{u}^{(i)}\left(a_{i}, \mathbf{a}_{-i}\right)=u^{(i)}\left(a_{i}, \mathbf{a}_{-i}\right)-T\left(a_{i}\right) a_{i}
$$

where there is no subscript for the tax. Each selfish agent maximizes over his action and takes into account his effect on his tax bill. The first-order condition for a selfish agent $i$ is:

$$
\widetilde{u}_{i}^{(i)}\left(a_{i}, \mathbf{a}_{-i}\right)=u_{i}^{(i)}\left(a_{i}, \mathbf{a}_{-i}\right)-T\left(a_{i}\right)-\frac{d T\left(a_{i}\right)}{d a_{i}} a_{i}=0 .
$$

Note that we now observe a tax avoidance effect $\left(d T\left(a_{i}\right) / d a_{i}\right) a_{i}$ because the actions will vary the tax rate.

We now show how an efficiency-inducing tax schedule $T^{*}($.$) may be found.$ Again, let $\mathbf{a}^{*} \equiv\left(a_{1}^{*}, a_{2}^{*}, \ldots, a_{n}^{*}\right)$ be the socially optimal vector of actions. We assume all $a_{i}^{*}$ are strictly positive. Without loss of generality, we re-label individuals so that

$$
0<\underline{a}<a_{1}^{*} \leq a_{2}^{*} \leq \ldots \leq a_{n}^{*} .
$$

After this re-labeling, we define, for any individual $i$, his "divergence of private marginal benefit from social marginal benefit" by

$$
\phi_{i} \equiv u_{i}^{(i)}\left(a=a_{i}^{*}, \mathbf{a}_{-i}^{*}\right)-W_{i}\left(a=a_{i}^{*}, \mathbf{a}_{-i}^{*}\right)
$$

Let us introduce the following assumption:

\footnotetext{
${ }^{7}$ In this model, the government knows that there are $n$ agents with $n$ (generally) distinct and known objective functions, but does not know which agent has which objective function. This also holds for each individual agent. This assumption is in line with the optimal taxation literature in which agents can pretend to be of a certain type but cannot invent a type which does not exist.

${ }^{8}$ Note that $T$ has no subscript because taxes no longer depend on individuals but are the same for all individuals who take the same level of actions.
} 


\section{Assumption A: (monotonicity)}

$$
0<\phi_{1} \leq \phi_{2} \leq \ldots \leq \phi_{n} .
$$

This assumption implies that the more an individual's private marginal benefit (evaluated at the social optimum) exceeds the social marginal benefit, the higher is his activity level. Note that the $\phi_{i}$ 's are (known) real numbers, not functions.

In view of inequalities (7) and (8), we can now construct a monotone non-decreasing function $\omega(a)$ which has the following properties: ${ }^{9}$

(i) $\omega\left(a_{i}^{*}\right)=\phi_{i}$ for $i=1,2, \ldots n$.

(ii) $\omega(a)$ is continuously differentiable, with derivative $\omega^{\prime}(a) \geq 0$.

Define the function

$$
\Omega(a) \equiv \int_{0}^{a} \omega(\widetilde{a}) d \widetilde{a}
$$

Notice that $\Omega(0)=0$, so that, as will be clear below, an agent who chooses $a=0$ will pay no tax. Our construction implies that

$$
\Omega^{\prime}(a)=\omega(a),
$$

hence, by property (i) above,

$$
\Omega^{\prime}\left(a_{i}^{*}\right)=u_{i}^{(i)}\left(a=a_{i}^{*}, \mathbf{a}_{-i}^{*}\right)-W_{i}\left(a=a_{i}^{*}, \mathbf{a}_{-i}^{*}\right) .
$$

Our tax function is now constructed as follows:

$$
a T(a) \equiv \Omega(a),
$$

The selfish individual $i$ 's first order condition (6) is then

$$
u_{i}^{(i)}\left(a_{i}, \mathbf{a}_{-i}\right)-\Omega^{\prime}\left(a_{i}\right)=0 .
$$

It follows that by choosing $a_{i}=a_{i}^{*}$, the individual achieves his private optimum (given the tax schedule), which coincides with the social optimum. The second order condition

$$
u_{i i}^{(i)}\left(a_{i}, \mathbf{a}_{-i}\right)-\Omega_{i}^{\prime}\left(a_{i}\right)=u_{i i}^{(i)}\left(a_{i}, \mathbf{a}_{-i}\right)-\omega^{\prime}\left(a_{i}\right)<0
$$

is satisfied because $u_{i i}^{(i)}<0$ and $\omega^{\prime} \geq 0$. We are now able to prove

\footnotetext{
${ }^{9}$ There are infinitely many functions that satisfy these properties. We may take any of them.
} 
Proposition 2 The social optimum can be achieved as a Nash equilibrium by applying a non-individualized tax scheme if Assumption A holds. The optimal tax scheme is independent of the vector of parameters $\theta_{i}$ that represents the degree of social responsibility.

Proof: The invariance follows easily from the optimal behavior of a socially responsible agent. His net payoff is

$$
V^{(i)}=\left(1-\theta_{i}\right)\left[u^{(i)}\left(a_{i}, \mathbf{a}_{-i}^{*}\right)-T\left(a_{i}\right)\right]+\theta_{i} W\left(a_{i}, \mathbf{a}_{-i}^{*}\right)
$$

and yields the first-order condition

$$
\left(1-\theta_{i}\right)\left[u_{i}^{(i)}\left(a_{i}, \mathbf{a}_{-i}^{*}\right)-T\left(a_{i}\right)-\frac{d T\left(a_{i}\right)}{d a} a_{i}\right]+\theta_{i} W_{i}\left(a_{i}, \mathbf{a}_{-i}^{*}\right)=0 .
$$

This condition is fulfilled for $a_{i}=a_{i}^{*}$ if tax scheme $a T(a) \equiv \Omega(a)$ is applied.

Let us illustrate our results by an environmental economics example with heterogeneous agents. Let $a_{i}$ be the amount of resources used by individual $i$, and let $Z=\sum a_{i}^{2}$ be the resulting pollution. Assume that individual $i$ 's utility function is

$$
u^{(i)} \equiv \delta_{i} \ln a_{i}-\frac{1}{4} Z^{2},
$$

where $0<\delta_{1}<\delta_{2}<\ldots<\delta_{n}$. Let social welfare be the sum of individual utility levels:

$$
W=\sum_{i=1}^{n} u^{(i)}=-\frac{n}{4} Z^{2}+\sum_{i=1}^{n} \delta_{i} \ln a_{i} .
$$

Define $\Delta \equiv \sum_{i=1}^{n} \delta_{i}$. The appendix proves that the optimal tax schedule is given by

$$
T(a)=\frac{(n-1) a}{2} \sqrt{\frac{\Delta}{n}} .
$$

This tax schedule will lead to an optimal allocation also if one, some or all agents are "green" in the sense that they partially take into account the effect of their resource use on others.

Our example also offers some guidance on the shape of the tax scheme. $T(a)$ in our example is linear in activity levels because the divergence between 
private marginal benefit and social marginal benefit is linear in $a,{ }^{10}$ and thus $\Omega(a)$ is quadratic. For other specifications, the divergence may be increasing in $a$ at an increasing (decreasing) rate, then we expect the optimal tax scheme will be progressive (regressive).

\section{Discussion}

We now discuss how our results may be extended to alternative specifications, and explore conditions under which our results may not hold true. Would the invariance property in Proposition 1 still hold if the utility functions are not quasi-linear? Suppose there are $F$ factors of production, $G$ final consumption goods, and $I$ individuals. Let $\alpha_{f}^{i}$ (respectively, $c_{g}^{i}$ ) be the amount of factor $f$ supplied by (respectively, final good $g$ consumed by) individual $i$. Suppose the utility function of individual $i$ is

$$
U^{(i)}=U^{(i)}\left(\alpha_{1}^{i}, \alpha_{2}^{i}, \ldots, \alpha_{F}^{i}, c_{1}^{i}, c_{2}^{i}, \ldots, c_{G}^{i}, \boldsymbol{\alpha}^{-i}, \mathbf{c}^{-i}\right)
$$

where $\boldsymbol{\alpha}^{-i}$ and $\mathbf{c}^{-i}$ are the vector of factor supplies and consumptions of other individuals. Suppose the social welfare function is

$$
W\left(\alpha_{1}^{1}, \alpha_{2}^{1}, \ldots, \alpha_{F}^{1}, c_{1}^{1}, c_{2}^{1}, \ldots, c_{G}^{1}, \alpha_{1}^{2}, \alpha_{2}^{2}, \ldots, \alpha_{F}^{2}, c_{1}^{2}, c_{2}^{2}, \ldots, c_{G}^{2}, \ldots\right) \equiv W(\boldsymbol{\alpha}, \mathbf{c})
$$

where all technological constraints have been taken into account. The socially optimal allocation, denoted by a hat, is assumed to be the unique solution of the $(F+G) I$ first order conditions, for $i=1,2, \ldots, I, f=1,2, \ldots, F$, $g=1,2, \ldots, G$,

$$
\begin{aligned}
& \frac{\partial W}{\partial \alpha_{f}^{i}}\left(\widehat{\alpha}_{1}^{1}, \widehat{\alpha}_{2}^{1}, \ldots, \widehat{\alpha}_{F}^{1}, \widehat{c}_{1}^{1}, \widehat{c}_{2}^{1}, \ldots, \widehat{c}_{G}^{1}, \widehat{\alpha}_{1}^{2}, \widehat{\alpha}_{2}^{2}, \ldots, \widehat{\alpha}_{F}^{2}, \widehat{c}_{1}^{2}, \widehat{c}_{2}^{2}, \ldots, \widehat{c}_{G}^{2}, \ldots\right)=0 \\
& \frac{\partial W}{\partial c_{g}^{i}}\left(\widehat{\alpha}_{1}^{1}, \widehat{\alpha}_{2}^{1}, \ldots, \widehat{\alpha}_{F}^{1}, \widehat{c}_{1}^{1}, \widehat{c}_{2}^{1}, \ldots, \widehat{c}_{G}^{1}, \widehat{\alpha}_{1}^{2}, \widehat{\alpha}_{2}^{2}, \ldots, \widehat{\alpha}_{F}^{2}, \widehat{c}_{1}^{2}, \widehat{c}_{2}^{2}, \ldots, \widehat{c}_{G}^{2}, \ldots .\right)=0 .
\end{aligned}
$$

Assume that corresponding to the optimal allocation, we can determine the (pre-tax) price of factor $f$ (denoted by $w_{f}$ ) and the (pre-tax) price of good $g$ (denoted by $p_{g}$ ), where $f=1,2, \ldots, F$ and $g=1,2, \ldots, G$. Let $\tau_{f}^{i}$ (respectively,

\footnotetext{
${ }^{10}$ See equation (A.3) in the appendix.
} 
$t_{g}^{i}$ ) be the individualized tax per unit of $\alpha_{f}^{i}$ (respectively, $c_{g}^{i}$ ). Assume that the consumption of good 1 does not generate externalities, so that $t_{1}^{i}=0$ for all $i$. Let $L_{i}$ be the lump sum transfer to individual $i$. The budget constraint of individual $i$ is then

$$
p_{1} c_{1}^{i}=L^{i}+\sum_{f}\left(w_{f}-\tau_{f}^{i}\right) \alpha_{f}^{i}-\sum_{g}\left(p_{g}+t_{g}^{i}\right) c_{g}^{i} .
$$

Consider for the moment the case where all individuals are selfish. The optimal taxes must ensure that the optimal allocation is implementable as a Nash equilibrium, i.e., for each $i$, the vector $\left(\widehat{\alpha}_{1}^{i}, \widehat{\alpha}_{2}^{i}, \ldots, \widehat{\alpha}_{F}^{i}, \widehat{c}_{1}^{i}, \widehat{c}_{2}^{i}, \ldots, \widehat{c}_{G}^{i}\right)$ maximizes individual $i$ 's utility

$$
\begin{aligned}
& U^{(i)}\left(\alpha_{1}^{i}, \alpha_{2}^{i}, \ldots, \alpha_{F}^{i}, \frac{L^{i}+\sum\left(w_{f}-\tau_{f}^{i}\right) \alpha_{f}^{i}-\sum\left(p_{g}+t_{g}^{i}\right) c_{g}^{i}}{p_{1}}, c_{2}^{i}, \ldots, c_{G}^{i}, \boldsymbol{\alpha}^{-i}, \mathbf{c}^{-i}\right), \\
& \text { i.e., for } f=1,2, \ldots, F \\
& \frac{\partial U^{(i)}}{\partial \alpha_{f}^{i}}\left(\alpha_{1}^{i}, \alpha_{2}^{i}, \ldots, \alpha_{F}^{i}, \frac{L^{i}+\sum\left(w_{f}-\tau_{f}^{i}\right) \alpha_{f}^{i}-\sum\left(p_{g}+t_{g}^{i}\right) c_{g}^{i}}{p_{1}}, c_{2}^{i}, \ldots, c_{G}^{i}, \boldsymbol{\alpha}^{-i}, \mathbf{c}^{-i}\right)=0
\end{aligned}
$$

and for $g=2, \ldots, G$

$$
\frac{\partial U^{(i)}}{\partial a_{g}^{i}}\left(\alpha_{1}^{i}, \alpha_{2}^{i}, \ldots, \alpha_{F}^{i}, \frac{L^{i}+\sum\left(w_{f}-\tau_{f}^{i}\right) \alpha_{f}^{i}-\sum\left(p_{g}+t_{g}^{i}\right) c_{g}^{i}}{p_{1}}, c_{2}^{i}, \ldots, c_{G}^{i}, \boldsymbol{\alpha}^{-i}, \mathbf{c}^{-i}\right)=0 .
$$

Setting the hat values $\widehat{\alpha}_{f}^{i}$ and $\widehat{c}_{g}^{i}$ into the system of $(F+G) I$ equations (10), (11) and (12), we can determine the $(F+G-1) I$ tax rates (recall that $\left.t_{1}^{i}=0\right)$ and $I$ lump sum transfer amounts $L^{i}$ for $i=1,2, \ldots, I$.

Now suppose some agents are socially responsible. Very generally, the objective function of a socially responsible agent can be written as the a function depending on the utility of a selfish agent and social welfare:

$$
V^{i}\left[U^{i}(\cdot), W(\cdot)\right], V_{U}^{i}>0, V_{W}^{i} \geq 0 .
$$

The utility of a selfish agent is a special case of $V^{i}$ for which $V_{W}^{i}=0$. The first-order conditions for a socially responsible agent are, for $f=1,2, \ldots, F$ and $g=2,3, \ldots, G$ 


$$
\begin{array}{r}
V_{U}^{i} \frac{\partial U^{(i)}}{\partial \alpha_{f}^{i}}\left(\alpha_{1}^{i}, \ldots \alpha_{F}^{i}, \frac{\sum_{f}\left(w_{f}-\tau_{f}^{i}\right) \alpha_{f}^{i}-\sum_{g \neq 1}\left(p_{g}+t_{g}\right) c_{g}^{i}}{p_{1}}, c_{2}^{i}, \ldots, c_{G}^{i}, \widehat{\boldsymbol{\alpha}}^{-i}, \widehat{\mathbf{c}}^{-i}\right)+ \\
V_{W}^{i} \frac{\partial W}{\partial \alpha_{f}^{i}}(\widehat{\boldsymbol{\alpha}}, \widehat{\mathbf{c}})=0, \\
V_{U}^{i} \frac{\partial U^{(i)}}{\partial c_{g}^{i}}\left(\alpha_{1}^{i}, \ldots \alpha_{F}^{i}, \frac{\sum_{i}\left(w_{i}-\tau_{i}\right) \alpha_{i}-\sum_{j \neq 0}\left(p_{j}+t_{j}\right) a_{j}}{p_{0}}, c_{2}^{i}, \ldots, c_{G}^{i}, \widehat{\boldsymbol{\alpha}}^{-i}, \widehat{\mathbf{c}}^{-i}\right)+ \\
V_{W}^{i} \frac{\partial W}{\partial c_{g}^{i}}(\widehat{\boldsymbol{\alpha}}, \widehat{\mathbf{c}})=0 .
\end{array}
$$

Clearly, the optimal tax vector when all agents are selfish is also optimal when some or all agents are socially responsible, since $\frac{\partial W}{\partial c_{g}^{i}}(\widehat{\boldsymbol{\alpha}}, \widehat{\mathbf{c}})=0$ and $\frac{\partial W}{\partial \alpha_{f}^{i}}(\widehat{\boldsymbol{\alpha}}, \widehat{\mathbf{c}})=0$. This analysis suggests that our basic results can be extended to intertemporal models as well, because we may consider the different activity levels as activity levels in time.

Furthermore, our model and results in Section 2 are also not affected when we introduce non-zero costs of public funds because the government cannot use lump-sum taxes to raise tax revenues. Let $\lambda \geq 0$ denote the shadow price of public funds. Welfare is equal to

$$
W=W\left(a_{1}, a_{2}, \ldots, a_{n}\right)+\lambda T,
$$

where $T=\sum_{n} t_{i} a_{i}$ is the tax revenue. If $\lambda>0$, the optimal tax vector will be different compared to the case of a zero shadow price of public funds. However, a socially responsible agent will also take this effect into account when deciding on his activity level. The first-order condition (5) will remain qualitatively unchanged, but it will change quantitatively with a change in the shadow price of public funds. Our invariance theorem (Proposition 1), however, is not affected.

The invariance theorem relies on the feasibility of taxing all relevant activities. If at least one activity which gives rise to an externality problem cannot be taxed (or subsidized), Proposition 1 will not hold. In this case, the tax scheme can only be second best as it can only indirectly influence untaxed activities. Obviously, in that case, the optimal tax will also depend on 
the degree of social responsibility. We should also mention that our invariance theorem will not hold under asymmetric information, for example in a Mirrlees-type optimal taxation model, because unobservable actions remain untaxed by definition. Finally, our invariance theorem fails if restribution should be achieved by taxation as well or if taxation should deal with effects of envy in a group at the same time unless this tradeoff can be dealt with by the specification of the welfare function $W$.

\section{Concluding remarks}

In this paper, we have developed a model in which individual agents are different in two dimensions. First, the payoffs they derive for themselves may differ due to different payoff functions. Second, the extent to which they take welfare aspects into account (their degree of social responsibility) may vary across individuals. We have shown that the degrees of social responsibility felt by individual agents have no bearing on the optimal tax rate and on the optimal allocation which is implemented as a Nash equilibrium. Hence, efficiency-inducing tax policy which may apply to any activity which creates an externality problem should take account of heterogeneity in terms of individual payoffs functions only, and not heterogeneity in terms of social responsibility.

We have also demonstrated that, under relatively mild assumption, nonindividualized tax schemes are insensitive to the degree of social responsibility. This is an important result as it demonstrates clearly that a social planner only needs to know the distribution of types in terms of the payoff functions. Unless certain activities cannot be taxed and these activities give rise to externalities, the social planner does not need to know the individuals' degree of social responsibility in order to be able to design optimal policies.

\section{Appendix}

In the absence of any regulation, each selfish individual will maximize $u^{(i)}$ by choosing $a_{i}$, taking $Z_{-i}$ as given. This leads to $n$ first-order conditions: 


$$
\delta_{i}=a_{i}^{2} Z .
$$

Adding up over all $n$ first order conditions leads to $\Delta=Z^{2}$. The unregulated Nash equilibrium in this game implies the aggregate pollution level of $Z=$ $\sqrt{\Delta}$. Each individual's resource use amounts to $a_{i}=\sqrt{\delta_{i} / Z}=\sqrt{\delta_{i} / \sqrt{\Delta}}$.

The socially optimal pollution level can be derived from maximization of $W$, which gives $n$ first-order conditions:

$$
W_{i}=\frac{\delta_{i}}{a_{i}}-n a_{i} Z=0 .
$$

Adding up all $n$ first-order conditions yields $\Delta=n Z^{2}$. Thus the socially optimal level of pollution is given by

$$
Z^{*}=\sqrt{\Delta / n}
$$

and the resulting optimal resource use, $a_{i}^{*}$, is

$$
a_{i}^{*}=\sqrt{\frac{\delta_{i}}{n Z^{*}}}=\sqrt{\frac{\delta_{i}}{\sqrt{n \Delta}}} .
$$

The marginal utility and the marginal welfare, computed at the optimal level of resource use, are respectively equal to

$$
u_{i}^{(i)}\left(a=a_{i}^{*}, \mathbf{a}_{-i}^{*}\right)=\frac{\delta_{i}}{a_{i}^{*}}-a_{i}^{*}\left[a_{i}^{* 2}+\sum_{j \neq i} a_{j}^{* 2}\right]=\frac{\delta_{i}}{a_{i}^{*}}-a_{i}^{*} Z^{*}
$$

and

$$
W_{i}\left(a=a_{i}^{*}, \mathbf{a}_{-i}^{*}\right)=\frac{\delta_{i}}{a_{i}^{*}}-n a_{i}^{*}\left[a_{i}^{* 2}+\sum_{j \neq i} a_{j}^{* 2}\right]=\frac{\delta_{i}}{a_{i}^{*}}-n a_{i}^{*} Z^{*} .
$$

Thus

$$
\phi_{i} \equiv u_{i}^{(i)}\left(a=a_{i}^{*}, \mathbf{a}_{-i}^{*}\right)-W_{i}\left(a=a_{i}^{*}, \mathbf{a}_{-i}^{*}\right)=(n-1) a_{i}^{*} Z^{*} .
$$

Expression (A.3) shows that Assumption A (monotonicity) is satisfied. We can then construct the function $\omega(a)=(n-1) a Z^{*}$. Integration lead to

$$
\Omega(a)=(n-1) Z^{*} \frac{a^{2}}{2}
$$


and the tax function is thus given by

$$
T(a)=\frac{\Omega(a)}{a}=\frac{(n-1) Z^{*} a}{2} .
$$

(Here, each individual treats $Z^{*}$ as given). Inserting $Z^{*}$ from (A.2) yields the tax function (A.4). Individual $i$, taking as given the tax function (A.4) and assuming that $j$ chooses $a_{j}^{*}$, finds that his first-order condition is

$$
\frac{\delta_{i}}{a_{i}}-a_{i}\left[a_{i}^{2}+\sum_{j \neq i}\left(a_{j}^{*}\right)^{2}\right]-(n-1) a_{i} \sqrt{\Delta / n}=0 .
$$

Choosing $a_{i}=a_{i}^{*}$ will satisfy this first-order condition. The second-order condition is also satisfied:

$$
-\frac{\delta_{i}}{a_{i}^{2}}-Z^{*}-2 a_{i}^{2}-(n-1) Z^{*}<0
$$

\section{References}

[1] Ackert, Lucy F., Jorge Martinez-Vazquez and Mark Rider, 2007, "Social Preferences and Tax Policy Design: Some Experimental Evidence," Economic Inquiry, 45: 487-501.

[2] Alesina, Alberto and George-Marios Angeletos, 2005, "Fairness and Redistribution, "American Economic Review, 95: 960-980.

[3] Arrow, Kenneth, 1970, "The Organization of Economic Activity: Issues Pertinent to the Choice of Market versus Non-market Allocation," in R. H. Haveman and J, Margolis (eds.), Public Expenditures and Policy Analysis, Chicago: Markham, pp. 59-73.

[4] Atkinson, Anthony B. and Joseph E. Stiglitz, 1976, "The Design of Tax Structure: Direct versus Indirect Taxation," Journal of Public Economics, 6: 55-75.

[5] Becker, Gary S., 1974, "A Theory of Social Interactions," Journal of Political Economy, 82: 1063-93. 
[6] Bergstrom, Theodore C., 1989, "A Fresh Look at the Rotten Kid Theorem - and Other Household Mysteries," Journal of Political Economy, 97: 1138-59.

[7] Bergstrom, Theodore C., Larry Blume and Hal R. Varian, 1986, "On the Private Provision of Public Goods," Journal of Public Economics, 29: 25-49.

[8] Coase, Ronald, 1960, "The Problem of Social Cost." Journal of Law and Economics, 3: 1-44.

[9] Fleurbaey, Marc and François Maniquet, 2006, "Fair Income Tax," Review of Economic Studies, 73: 55-83.

[10] Fleurbaey, Marc and François Maniquet, 2007, "Help the Low Skilled or Let the Hardworking Thrive? A Study of Fairness in Optimal Income Taxation," Journal of Public Economic Theory, 9: 467-500.

[11] Groves, Theodore and John Ledyard, 1977, "Optimal Allocation of Public Goods: A Solution to the "Free Rider" Problem," Econometrica, 45: 783-809.

[12] Moore, John, 1992, "Implementation, Contracts, and Renegotiation in Environments with Complete Information," in Jean-Jacques Laffont (ed.) Advances in Economic Theory: Sixth World Congress, Cambridge: Cambridge University Press, pp. 182-281.

[13] Moore, John and Repullo, Rafael, 1988, "Subgame Perfect Implementation," Econometrica, 56: 1191-1220.

[14] Nishimura, Yukihiro, 2004, "Tax implementability of fair allocations," Review of Economic Design, 9: 31-41.

[15] Pigou, A.C., 1920, The Economics of Welfare, first edition, Macmillan, London.

[16] Varian, Hal R., 1994, "A Solution to the Problem of Externalities when Agents are well-informed," American Economic Review, 84: 1278-1293. 